\title{
Microstructural Modeling of Thermally-Driven $\beta$ Grain Growth, Lamellae \& Martensite in Ti-6Al-4V
}

\author{
Matteo Villa, Jeffery W. Brooks, Richard P. Turner, Mark Ward \\ School of Metallurgy \& Materials, University of Birmingham, Birmingham, UK \\ Email: r.p.turner@bham.ac.uk, matteovilladr@gmail.com
}

How to cite this paper: Villa, M., Brooks, J.W., Turner, R.P. and Ward, M. (2020) Microstructural Modeling of Thermally-Driven $\beta$ Grain Growth, Lamellae \& Martensite in Ti-6Al-4V. Modeling and Numerical Simulation of Material Science, 10, 55-73.

https://doi.org/10.4236/mnsms.2020.103004

Received: June 4, 2020

Accepted: July 14, 2020

Published: July 17, 2020

Copyright $\odot 2020$ by author(s) and Scientific Research Publishing Inc. This work is licensed under the Creative Commons Attribution International License (CC BY 4.0).

http://creativecommons.org/licenses/by/4.0/

\begin{abstract}
The microstructural kinetics of $\beta$ grain growth in the $\beta$ field of a Ti-6Al-4V alloy was studied by a series of controlled heat treatments at constant temperature rates. Heating rates of $5^{\circ} \mathrm{C} / \mathrm{s}, 50^{\circ} \mathrm{C} / \mathrm{s}$ and $500^{\circ} \mathrm{C} / \mathrm{s}$ were considered, stopping at different peak temperatures. The thickness evolution of martensitic needles and lamellar $\alpha$ laths, formed on cooling, was also investigated, by soaking the material above its $\beta$-transus temperature and cooling down at $5^{\circ} \mathrm{C} / \mathrm{s}, 50^{\circ} \mathrm{C} / \mathrm{s}, 100^{\circ} \mathrm{C} / \mathrm{s}$ and $300^{\circ} \mathrm{C} / \mathrm{s}$ till ambient temperature. Quantitative microstructural analyses were used to measure the particle dimensions. The $\beta$ grain growth kinetics was reasonably well described by a modified Avrami equation. The thickness of $\alpha$ lamellae was a function of the cooling rate and the $\beta$ grain dimension in which they nucleated. The martensite needle thickness was shown to be a function of the cooling rate to which the material was subjected.
\end{abstract}

\section{Keywords}

Titanium, Welding, Rapid Heating, Phase, Alpha, Beta

\section{Introduction}

To optimize the performance of components subjected to thermal cycles induced by manufacturing processes, numerical simulation has become an increasingly popular tool amongst academia and industry. Numerical modeling offers a methodology to further process understanding, while reducing experimental costs, by studying component behaviors virtually during manufacturing simulations. Titanium alloys are widely utilized in high performance applications, and $\mathrm{Ti}-6 \mathrm{Al}-4 \mathrm{~V}$ is one of the most commonly encountered [1].

Manufacturing processes such as welding, which subject the component to a 
wide range of temperatures, temperature gradients and temperature rates, will induce variation of phase and precipitate sizes within the microstructure. In order to correctly simulate these, numerical models must consider the different phase fields as they develop and evolve.

Most components are not net-shape manufactured and thus require some joining procedures to successfully fabricate them. The selection of the relevant joining method is critical, and must take into consideration both the material and the component service condition. Welding is one of the most common metallurgical joining methods, and can produce components which are lighter, have lower manufacturing cost and improved structural integrity compared with other methods (e.g. riveting) [2]. However, in order to produce a welded joint with excellent properties, it is necessary to consider the thermal, mechanical, metallurgical and fluid dynamics fields to successfully optimize the process.

The equations describing these thermal, mechanical and material phenomena are so complex that simple analytical solutions are typically insufficient to predict the behavior of a welding process with the accuracy required to ensure the performance of the resulting joint [2]. In particular, the mechanical properties of materials are strongly dependent upon their microstructure, which in turn is controlled by the temperature fields and time-at-temperature. The need for more accurate solutions is being met with the use of methods such as finite element (FE) analysis, where structure is discretised into small elements and time-steps. The governing equations are then solved numerically over these discrete conditions. The use of finite element methods has been increasing over the past 50 years, aided by the increasing computing power available, allowing improved analysis of welding and other processes.

Sysweld, and its accompanying pre- and post-processing modules "Visual-Weld" (ESI Group), are a specialist FE welding simulation tool which contains microstructural modeling codes. The initial metallurgical code was based on the works of Avrami [3], who developed a general theory for phase change in steels, and subsequently added transformation-time dependence [4] and microstructure kinetics [5]. This has been extended further to also consider aluminium alloys [6]. Phase proportion evolution is described by phenomenological equations. However, due to the coupled nature of thermal, mechanical and metallurgical fields, it is important to predict the morphology of the microstructure developed during the process [7], and in particular the dimensions of spherical, lamellar and acicular particles [8], with effect of cooling rate [9] considered for the greatest modeling accuracy.

A number of authors have considered alpha and beta phase properties, and lamellar versus equiaxed grain effects occurring during thermal processing of titanium alloys, due to their significant aerospace engineering importance. Guo et al. [10] considered strain rates of high-temperature dynamic alpha to beta transformations, and their impact upon flow softening. Transformations during torsional loading were also considered [11]. Jonas et al. [12] explicitly measured volume fractions to determine a transformation volume fraction in the $975^{\circ} \mathrm{C}$ to 
$1025^{\circ} \mathrm{C}$ temperature range, for $\mathrm{Ti}-6 \mathrm{Al}-4 \mathrm{~V}$. This is responsible for the decrease in the flow curve level after the peak during straining. Wang et al. [13] observed an increase in the $\beta$-phase transformed when a near $\alpha$ alloy was deformed. Whilst Matsumoto [14] proposed that the increase in $\beta$-phase within an equiaxed microstructure led to stress concentrations at grain boundaries. Lutjering [15] classified the $\alpha$ colony size as the most important microstructural parameter in determining the mechanical properties of $\alpha+\beta$ titanium alloys, such as Ti-6Al- $4 \mathrm{~V}$, with the smaller $\alpha$ size giving rise to improved yield strength and ductility.

Different strategies for numerical modeling of the titanium alloy flow behavior under high thermal loads have been reported. A crystal plasticity framework was reported by Fan [16] with reasonable success in predicting the flow behavior. Babu and Lindgren [17] composed a dislocation density modeling framework to capture the effects of transformation upon material property. Whilst Basoalto modeled the high temperature micro-mechanics of slip in two-phase titanium alloys using crystal plasticity [18] and multi-physics ICME-type modeling frameworks [19].

More general microstructure modelling work for high temperature $\alpha+\beta$ titanium alloys has been performed for specific processing conditions or manufacturing routes. These include; 1) hot rolling [20] with ABAQUS 3D modeling software implemented using UMAT subroutines, 2) tensile testing [21] using modified Johnson-Cook, modified Arrenhius and modified Zerilli-Armstrong approaches to predict flow stress behavior, and 3) Ultrasonic cutting [22], using a 2D modeling framework with a Johnson-Mehl-Avrami-Kolgomorov (JMAK) microstructure model to simulate the two-phase alloy behavior.

Thus, there is considerable academic interest with the experimental measurement methods and numerical modeling of the microstructure evolution of two-phase titanium alloys at elevated temperature, and the impact this has upon mechanical properties. Literature does suggest the influence of the two-phase $\alpha$ and $\beta$ microstructure features such as $\alpha$ lamellar size and $\beta$ grain size is considerable [15] [23]. As such, the aim of this work is to show $\beta$ grain growth evolution in the $\beta$ field and $\alpha$ lamellar and martensitic needles growth in the $\alpha+\beta$ field, when cooling down from temperatures above $\beta$-transus. These phenomena are experimentally investigated and numerically described by empirical relationships.

\section{Material and Experiment}

\subsection{Material}

The material used in this study was a $16 \mathrm{~mm}$ thick Ti-6Al-4V plate, with a measured chemical composition by optical emission spectrometry, as given in Table 1. Two different types of specimens have been used for the experimental tests, in order to apply the heat treatments desired. Both tensile specimens (measuring $110 \mathrm{~mm}$ length by $6 \mathrm{~mm}$ diameter), and compressive specimens (16 mm length and $12 \mathrm{~mm}$ diameter) were machined. A glass coating was applied over each sample, before the heat treatments, as protection against oxidation. 
Table 1. Composition of the titanium alloy, in wt\%.

\begin{tabular}{ccccccc}
\hline $\mathrm{Al}$ & $\mathrm{V}$ & $\mathrm{Fe}$ & $\mathrm{H}$ & $\mathrm{N}$ & $\mathrm{O}$ & $\mathrm{Ti}$ \\
\hline 5.75 & 3.96 & 0.07 & 0.0045 & 0.013 & 0.11 & Bal. \\
\hline
\end{tabular}

The microstructure of the material as received after etching using aqueous $2 \%$ $\mathrm{HF}$ and $10 \% \mathrm{HNO}_{3}$ etchant is shown in Figure 1. This and all the microstructures presented were determined via backscattered electron imaging (BEI) by using an Oxford Instrument XL30 ESEM EG scanning electron microscope (SEM). The $\alpha$ phase features were identified by darker colors since it contains less dense elements (Aluminium atomic mass $26.9 \mathrm{~g} / \mathrm{mol}$ ), and lighter colors for $\beta$ phase features (Vanadium atomic mass $50.94 \mathrm{~g} / \mathrm{mol}$ ).

The $\beta$-transus temperature of the alloy was measured by soaking small cubic specimen $10 \times 15 \times 2 \mathrm{~mm}^{3}$ in a furnace for 20 minutes at temperatures around the nominal $\beta$-transus. The samples were glass coated before the heat treatment to reduce the oxygen pick-up at high temperatures, and water quenched after soaking to freeze the microstructure. The sample temperature was measured with a thermocouple placed in contact with the samples and controlled by data-logger connected to a personal computer, enabling real-time temperature measurement. The furnace temperature was then manually controlled with small temperature increments.

The temperatures tested were $960^{\circ} \mathrm{C}, 970^{\circ} \mathrm{C}$ and $980^{\circ} \mathrm{C}$. Optical microscopy using a Zeiss Axioskop 2 MAT microscope with software AxioVision v 4.6.3.0, and backscattered SEM investigations were carried out to determine when the sample had passed through the $\beta$-transus temperature, by observation of any remaining primary $\alpha$ lamellae. From Figure 2, it is evident that at $980^{\circ} \mathrm{C}$ the microstructure was completely transformed to $\beta$, since no parent microstructure can be observed and only martensite is present. This parent microstructure is most evident in the $960^{\circ} \mathrm{C}$ image, where the globular $\alpha$-phase can be evidenced, particularly in the back-scattered SEM image. Thus, it is clear that at the $960^{\circ} \mathrm{C}$ and $970^{\circ} \mathrm{C}$ temperatures the sample still retains evidence of the parent microstructure. The $\beta$-transus temperature can thus be estimated to be in the range of $970^{\circ} \mathrm{C}$ to $980^{\circ} \mathrm{C}$.

\subsection{Rapid Heat Treatment Experiments}

In order to study the heat treatments presented, the fully integrated digital closed loop control thermal-mechanical testing system Gleeble 3500, produced by Dynamic System Inc was used. This experiment was carried out with the Gleeble under load control. A small load was applied to the samples to ensure electrical contact between samples and grip.

The Gleeble can apply compressive or tensile loadings on a specimen, whilst the controlled current is applied. Using the Joule effect, the component is heated following specified heating rate ramps, and then quenched using two nozzles to spray water directly on to the sample, to freeze the material microstructure. The 
sample geometries were chosen as they allowed the required temperature ramp rate at the largest specimen cross-section.

\subsubsection{Tensile Specimen}

A thin tensile dogbone specimen was used, which allowed faster heat treatments due to the lower volume of material. Three B-type thermocouples were spot welded on the tensile specimens, at the mid-length location, 4 and $8 \mathrm{~mm}$ away from the mid-length respectively, allowing thermal feedback to the Gleeble machine. As the Gleeble creates a parabolic heat distribution with the peak in the centre of the sample, three different heat treatments could be obtained from testing each specimen.

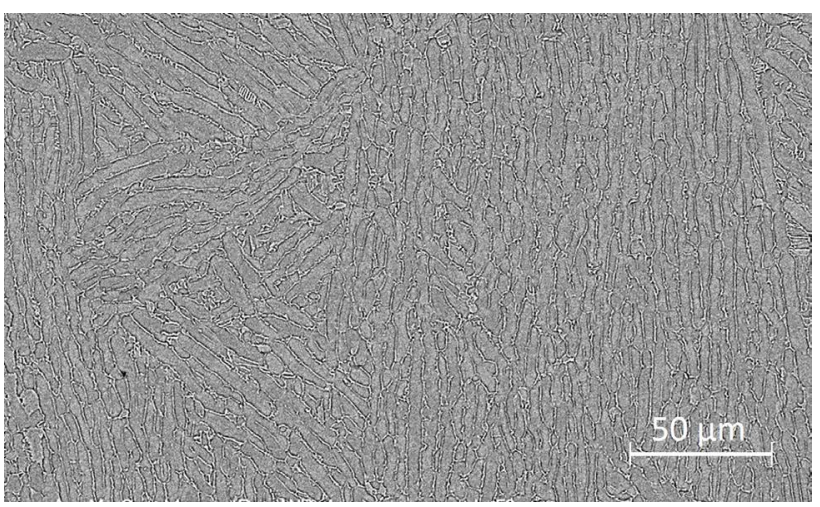

Figure 1. Backscattered SEM microstructure of the material as received. $\alpha$ lamellae are the darker areas, since they have lower atomic weight. The $\beta$ phase is the thin white boundaries.
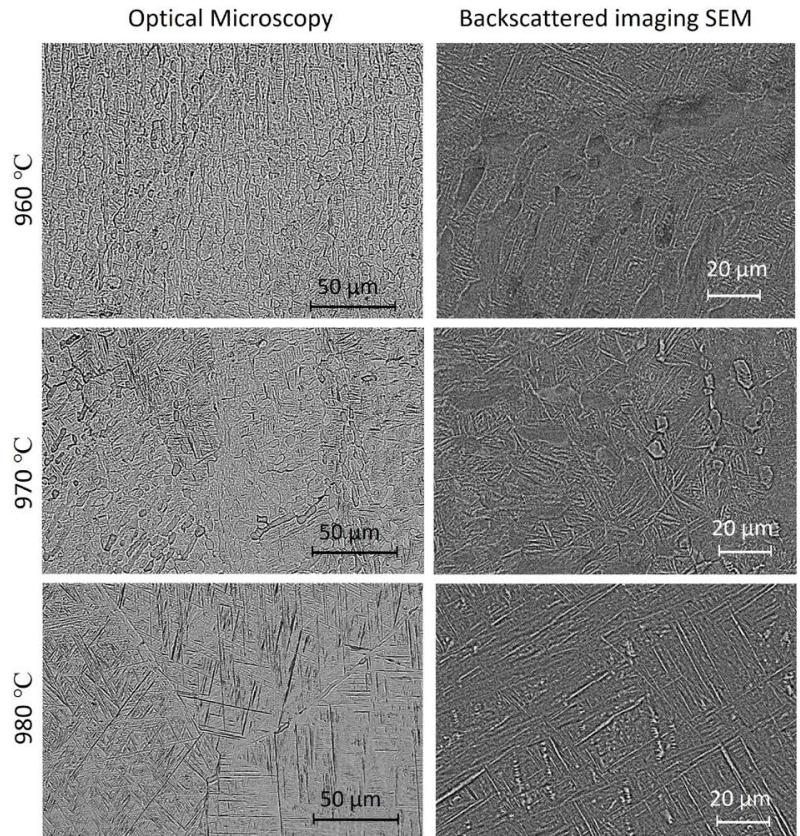

Figure 2. (left) optical, and (right) backscattered SEM images of the microstructure present in samples after soaking at $960^{\circ} \mathrm{C}$, $970^{\circ} \mathrm{C}$, and $980^{\circ} \mathrm{C}$. 
Numerical simulations using FE software Deform v11.0 were carried out, with thermal histories at points (P1-6) to represent the 3 thermocouple locations, to verify that the thermal gradients were reasonable. At a simulated heating rate of $360^{\circ} \mathrm{C} / \mathrm{s}$, the maximum difference in temperature between the surface and the centre of the tensile specimen was predicted to be $11^{\circ} \mathrm{C}$ (Figure 3(a)), a value considered acceptable and within possible tolerance errors related to temperature measurements, sectioning and microstructure measurement.

\subsubsection{Compressive Specimen}

A larger cross-section specimen was important for tests conducted at temperatures higher than the $\beta$ transus temperature, to ensure sufficient $\beta$ grains could be measured for microstructural analysis. In fact, when the temperature rises above the $\beta$ transus temperature the $\beta$ grains dimension tends to a magnitude of millimetres. Further cylindrical compression specimens of size $10 \times 10 \times 2 \mathrm{~mm}^{3}$ were machined for compression testing. Only one type-B thermocouple was spot welded on compressive specimens, at the mid-length, since being much shorter, the thermal gradient along their length was too pronounced increasing the uncertainty in measurements away from their mid-length.

To check the temperature along the thickness of the compression samples another Deform FE model was considered (Figure 3(b)). At the peak temperature of the simulation, with a heating rate of about $70^{\circ} \mathrm{C} / \mathrm{s}$, the difference in temperature between surface and centre of the specimen was $26^{\circ} \mathrm{C}$, still believed to be acceptable, considering also that at lower temperatures this difference becomes smaller; at the $\beta$-transus it is $20^{\circ} \mathrm{C}$.
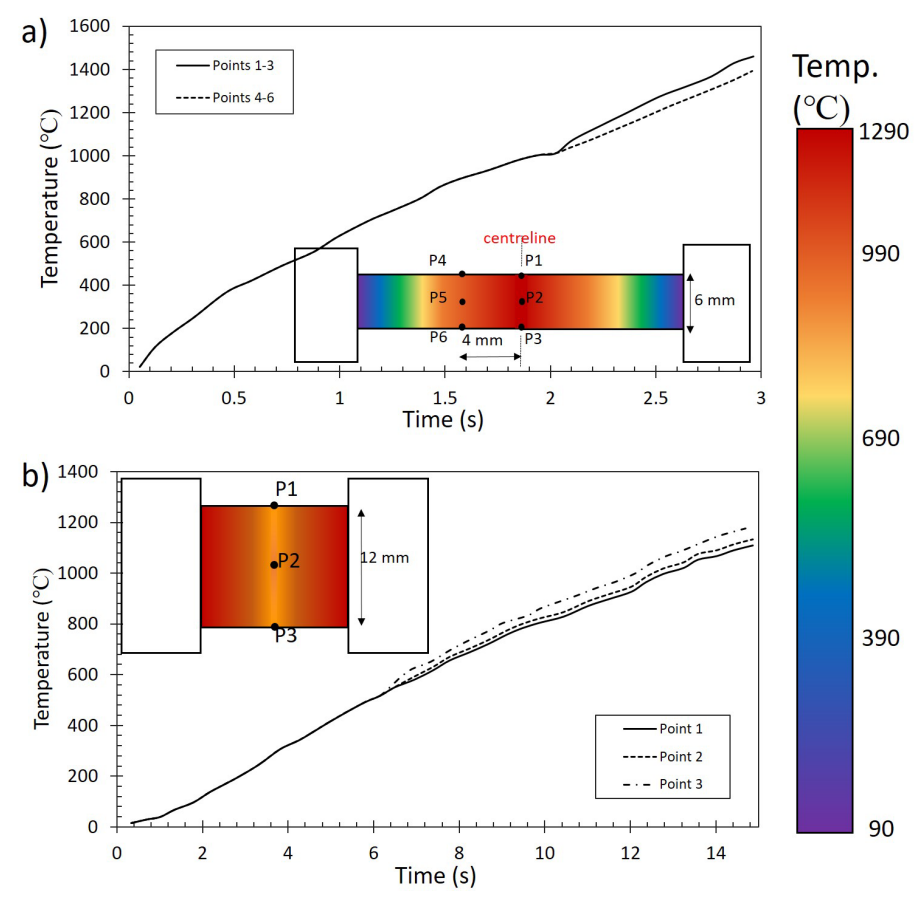

Figure 3. Modeled temperature distribution at specific locations for; (a) tensile Gleeble samples, and (b) compressive samples, applying a voltage potential of 2 V. Points considered for thermal histories are indicated with P notations. 


\subsubsection{Image Analysis}

After each test, the samples were sectioned at the plane of the thermocouple location, polished using a Struers diamond polishing paste, etched in 2\% $\mathrm{HF}$ and $10 \% \mathrm{HNO}_{3}$ solution and analyzed optically and with back scattered electron imaging (BEI). Montages of the entire section of each sample were composed, and the $\beta$ grain dimensions measured. Using ImageJ image processing software, the thickness of lamellar microstructure and volume fraction of $\alpha$ and $\beta$ phases were estimated.

For the estimation of the dimensions of $\beta$ grains, the following procedure was adopted: 1) Identification of the grain boundaries by manually highlighting their boundaries drawing black or white lines (see Figure $4(a)$ ), 2) the image was thresholded (Figure 4(b)), 3) Using an ImageJ routine, ellipses were inscribed as best as possible in each $\beta$ grain, such that the area of each ellipse was equivalent to the grain being evaluated (see Figure $4(\mathrm{c})$ ), 4) for each ellipse, a fictitious prolate spheroid volume was calculated, with the two smaller principal axis of the ellipsoid as the length of the minor axis, while the major axis of the ellipsoid was equivalent to the major axis. The mean value of the distribution of ellipsoid volumes was calculated and used as a representative value of the $\beta$ grain volume obtained from the heat treatment considered. For each ellipsoid an equivalent sphere in volume was calculated and the relative radius used as representative of the $\beta$ grain size distribution, thus simplifying the particle geometry into spheres.

In order to estimate the thickness of the $\alpha$ lamellae and martensitic needles nucleated during heat treatments, lines perpendicular to the longitudinal direction of the lamellae were traced, from one side to the other of each lamellae. However the aspect ratio was not measured as the length of the lamellae was often difficult to recognize, due to the intersecting martensitic structure developed during quenching. Measured values have been collated, and where more measurements were involved error bars represent the standard deviation.

As lamellar width may vary slightly in different three-dimensional orientations, so the method of using a 2D measurement plane considered here served to average the effect of the 3D variability measuring several lamellae must introduce. Thus the experimental method provides a potential source of variability and uncertainty. The phase volume fractions were estimated by thresholding pictures on the grey scale of the $\beta$ phase, represented by a whiter color in BEI pictures.
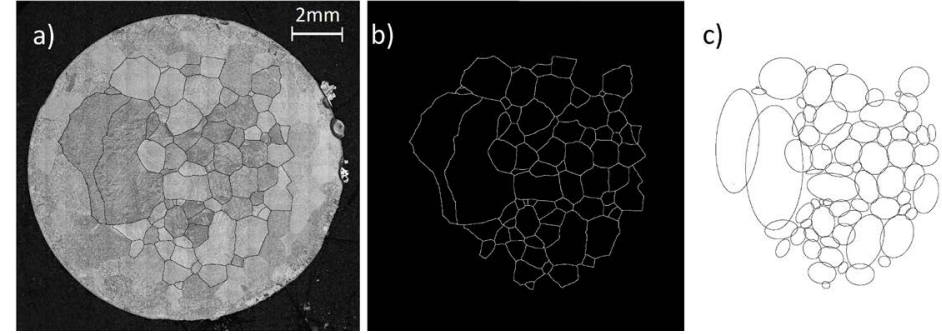

Figure 4. (a) $\beta$ grains manually highlighted; (b) $\beta$ grains thresholded; (c) ellipses inscribed in $\beta$ grains. 


\section{Results}

\subsection{Cooling Rate Effect on Lamellar and Martensitic Microstructure}

For the study of the cooling rate effect on the lamellae growth, during a continuous cooling from the $\beta$ field, both compression and tensile tests were conducted on the Gleeble, using the 2 specimen types as described earlier, based on the cooling rates required. Trends of the data obtained are shown in Figure 5(a) Figure $5(\mathrm{~b})$ as a function of the peak temperature from which the cooling started and in Figure 5(c) Figure 5(d) showing the $\beta$ grain size where the lamellar or martensitic microstructure nucleated. The error bars used illustrate the range of measurements from samples at specific cooling rates and temperatures.

Despite the sparse data set, it is apparent that the cooling rate from a specific temperature to ambient temperature does not have as pronounced an effect upon the lamellae thickness as the starting temperature at which the heat treatment happens has. This can be attributed to the different $\beta$ grain size in which the lamellae grow: the larger the $\beta$ grains, the greater the probability of a large distance between nucleated lamellae such that they can grow without chemically or mechanically influencing a neighboring lamella. Once two neighboring lamellae contact, the fast cooling rate do not leave time for coarsening. To verify this hypothesis, another set of thermal tests was conducted, testing a range of different starting $\beta$ grain sizes for each cooling rate. The relation between $\beta$ grain size and lamellar thickness seems to agree with the literature, even if information about this relationship is sparse [24]. On plotting the data acquired for the lamellar thickness as a function of the $\beta$ grain size, where the lamellae grew, in Figures 5(c)-(d), the hypothesis is supported.

The lamellar thickness seems to be unrelated to the cooling rate in continuous cooling heat treatments as; 1) thinner lamellae are not observed at the higher cooling rates, and 2) the thicker lamellae are measured for the fastest cooling rate $\left(300^{\circ} \mathrm{C} / \mathrm{s}\right)$, where the $\beta$ grains were noticeably bigger than those at slower cooling rates $\left(5^{\circ} \mathrm{C} / \mathrm{s}\right.$ and $\left.50^{\circ} \mathrm{C} / \mathrm{s}\right)$. Moreover, looking at the data relative to the cooling rate of $100^{\circ} \mathrm{C} / \mathrm{s}$, where a set of points with different $\beta$ grains has been collected, the relationship between peak temperature/dimension of the $\beta$ grains and lamellae thickness is very clear.

Finally, the inter lamellar $\beta$ phase is a function of the $\beta$ grain dimensions, where the $\beta$ phase thickens as the $\beta$ grains grow, such that the spacing between each lamella is driven by the $\beta$ grain size where they nucleate. This further supports the original hypothesis.

Using backscattered electron microscopy, the microstructures developed by the different cooling rates presented a higher amount of martensite and thicker martensitic needles as the cooling rate increased (see Figure 6). In Figure 6(a) the microstructure is observed to be fully lamellar, in Figure 6(b) martensite phase starts to form, Figures $6(\mathrm{c})$-(d) shows a fully martensitic microstructure, with thicker needles observed in d). In c) a grain boundary runs centrally, showing different orientation to the section plane of the martensitic needles. 

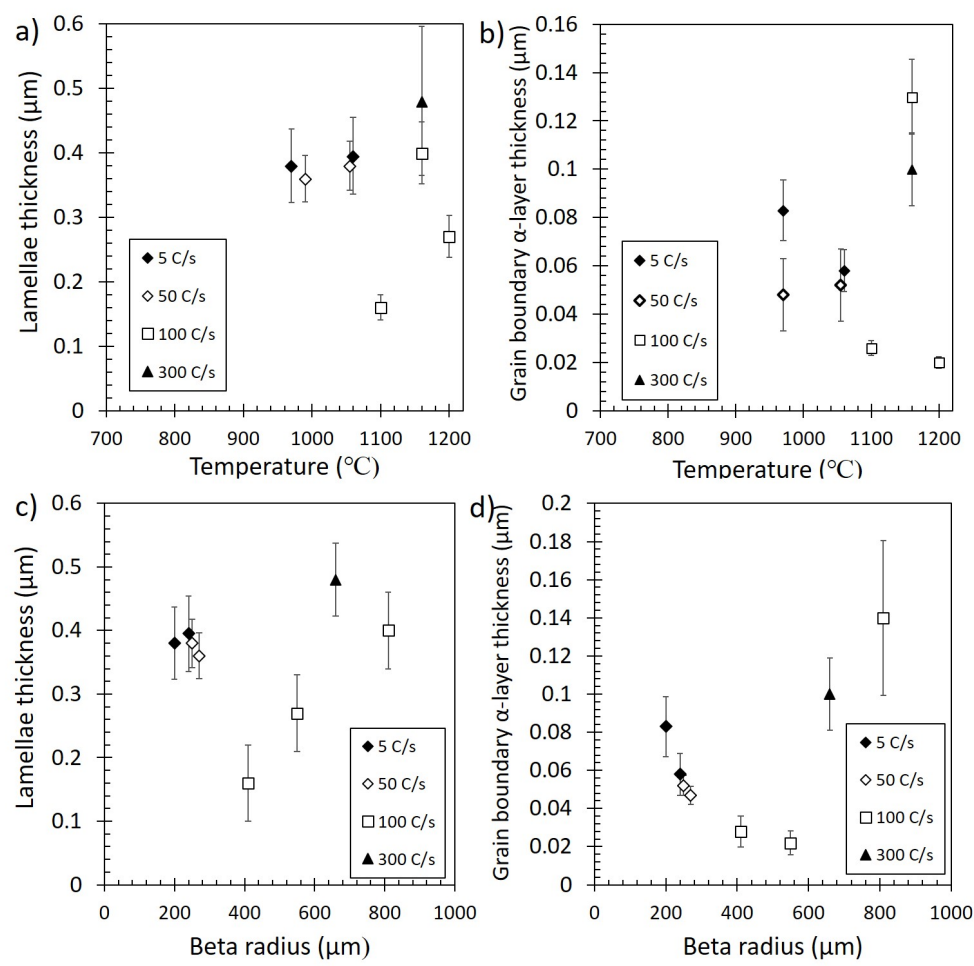

Figure 5. (a) Cooling rate effect on $\alpha$ lamellae thickness, (b) cooling rate effect on grain-boundary $\alpha$-layer, as a function of initial temperature, (c) cooling rate effect on $\alpha$ lamellae thickness, (d) cooling rate effect on grain-boundary $\alpha$-layer, as function of $\beta$ grain size.
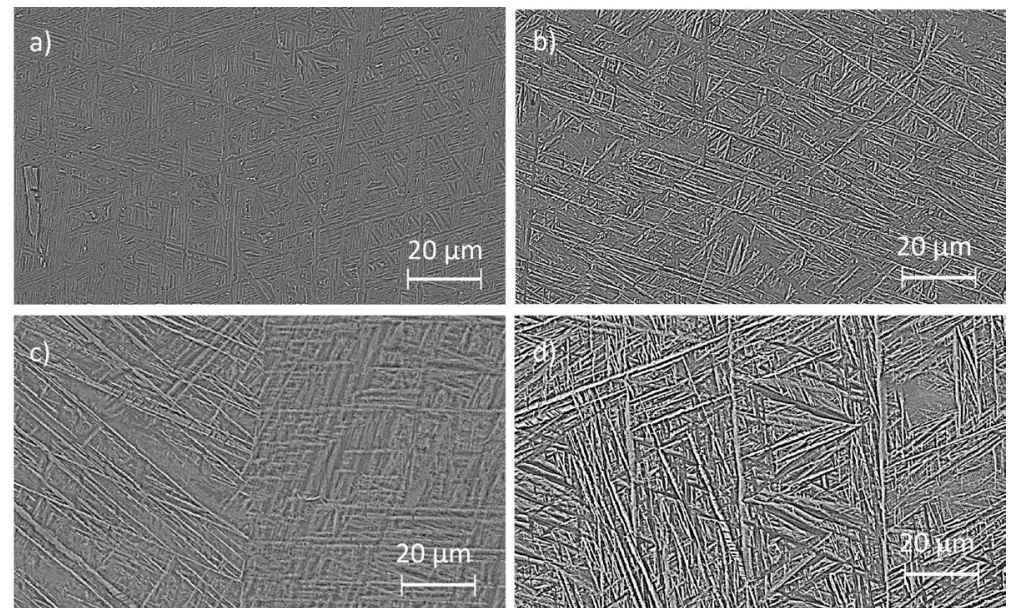

Figure 6. BEI micrographs showing microstructure observed after cooling the material from temperatures exceeding the beta transus at rates of; (a) $5^{\circ} \mathrm{C} / \mathrm{s}$, (b) $50^{\circ} \mathrm{C} / \mathrm{s}$, (c) $100^{\circ} \mathrm{C} / \mathrm{s}$, (d) $300^{\circ} \mathrm{C} / \mathrm{s}$.

Further image analysis has allowed for measurement of the needle thickness and $\alpha$ volume fraction, which are plotted as a function of cooling rate, see Figure 7. Significantly a logarithmic relationship was observed between needle thickness and cooling rate used to bring the samples from the tested temperature to ambient. The incomplete martensitic microstructure observed at cooling rates of 
$300^{\circ} \mathrm{C} / \mathrm{s}$ seems to confirm findings in the literature (Ahmed and Rack) [25], where a cooling rate of $500^{\circ} \mathrm{C} / \mathrm{s}$ is reported to be necessary to have the microstructure completely transformed to martensite.

TEM analysis would be required to better classify the lamellar $\alpha$ cooled at $300^{\circ} \mathrm{C} / \mathrm{s}$. In the literature [25] the $\alpha$ microstructure present at cooling rates exceeding $20^{\circ} \mathrm{C} / \mathrm{s}$ were analyzed by TEM and classified as a new $\alpha$ morphology, with a heavily dislocated internal substructure and the same hexagonal crystal structure as martensite. In absence of further investigation, the lamellae observed here by SEM are classified as the same typology.

\subsection{Growth of Nucleated Lamellae in the $\alpha+\beta$ Field}

To study the isothermal growth of lamellae in the $\alpha+\beta$ field, nucleated by cooling from the $\beta$ field, a set of experiments were carried out and analyzed. Samples were cooled from the $\beta$ field at a range of cooling rates and to different temperatures below the $\beta$-transus temperature. Samples were then water quenched directly, or soaked for 10 or 20 seconds followed by water quench. The experimental parameters used are given in Table 2 . A full-factorial $(3 \times 3)$ matrix of the cooling rate and soak time parameters at $910^{\circ} \mathrm{C}$ was used, whilst the $5^{\circ} \mathrm{C} / \mathrm{s}$ rate was focused upon at the other soak temperatures. This allowed for the most efficient comparison of the different processing parameter influences.

Table 2. Parameters used for the experiments to study growth of lamellae in the $\alpha+\beta$ field on cooling.

\begin{tabular}{|c|c|c|c|}
\hline Experiment No. & Temperature $\left({ }^{\circ} \mathrm{C}\right)$ & Cooling rate $\left({ }^{\circ} \mathrm{C} / \mathrm{s}\right)$ & Soak time before quench (s) \\
\hline 1 & 970 & 5 & 0 \\
\hline 2 & 970 & 5 & 10 \\
\hline 3 & 970 & 50 & 0 \\
\hline 4 & 970 & 50 & 10 \\
\hline 5 & 950 & 5 & 0 \\
\hline 6 & 950 & 5 & 10 \\
\hline 7 & 950 & 5 & 20 \\
\hline 8 & 910 & 5 & 0 \\
\hline 9 & 910 & 5 & 10 \\
\hline 10 & 910 & 5 & 20 \\
\hline 11 & 910 & 25 & 0 \\
\hline 12 & 910 & 25 & 10 \\
\hline 13 & 910 & 25 & 20 \\
\hline 14 & 910 & 50 & 0 \\
\hline 15 & 910 & 50 & 10 \\
\hline 16 & 910 & 50 & 20 \\
\hline
\end{tabular}



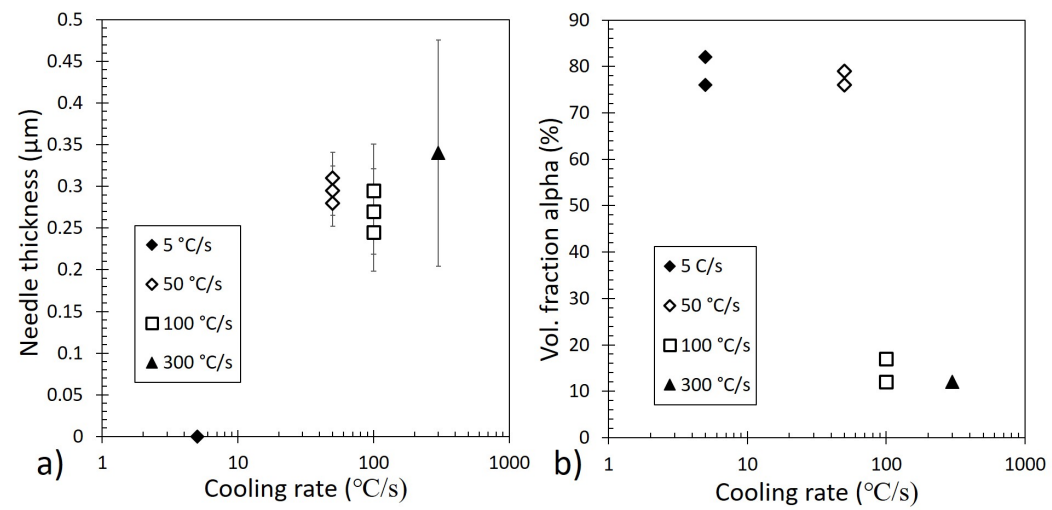

Figure 7. (a) Needle thickness as a function of cooling rate; (b) $\alpha$ phase volume fraction as a function of cooling rate.

This experiment was undertaken to assess the feasibility of differentiating between $\alpha$ phase formed on cooling through the $\beta$-transus and the martensite produced on quenching. A distinction of these two microstructures is required for predicting mechanical properties. Due to the particular heat treatment carried out, a mixture of martensite and $\alpha$ lamellar microstructure was obtained, giving complicated Backscattered Electron Images (BEI) for analysis. The amount of $\alpha$ lamellae recognizable per specimens was also very low, which resulted in a small sample population (see Figure 8).

All experiments seems to show a slow growth of lamellae thickness as the soaking time in the $\alpha+\beta$ field increases; for all soaking temperatures, see Figure 9(a), although the results for the $910^{\circ} \mathrm{C}$ temperature appear to show very little change with time up to $20 \mathrm{~s}$. At the $50^{\circ} \mathrm{C} / \mathrm{s}$ cooling rate the increasing lamellae thickness seems more pronounced after $20 \mathrm{~s}$, but the low number of lamellae sampled per test make this difficult to confirm (see Figure 9(b)), and overall the lamellae thickness sensitivity to both cooling rate and soak temperature is very small.

\subsection{Beta Grain Growth}

As discussed earlier, the $\beta$ grain dimensions have been measured for specimens tested at different heating rates, to construct an analytical expression which describes their growth evolution. The measured experimental results for $\beta$ phase radius, as a function of peak temperature and of time, are shown in Figure 10, for the 3 heating rates tested $\left(5^{\circ} \mathrm{C} / \mathrm{s}, 50^{\circ} \mathrm{C} / \mathrm{s}\right.$ and $\left.500^{\circ} \mathrm{C} / \mathrm{s}\right)$.

Notice that at the fastest heating rate the $\beta$ grain dimension remains almost constant, limited by the short time-at-temperature during the heat treatment. At the intermediate heating rate of $50^{\circ} \mathrm{C} / \mathrm{s}$, comparing the same peak temperatures it is evident that the kinetics of the diffusion process driving the $\beta$ grain growth can now occur for long enough to return $\beta$ grain dimensions similar to those obtained for the slowest heating rate $\left(5^{\circ} \mathrm{C} / \mathrm{s}\right)$.

The asymptotic trends registered in these tests are in agreement with the ones 
reported in literature [26]. They can be attributed to the $\beta$ grain growth competition, where grain patterns of highly mis-oriented $\beta$ grains of similar dimension struggle to combine. Moreover, a slower growth rate can be supported also by a progressive homogenization of the chemical field as the growth proceeds under non-equilibrium conditions.

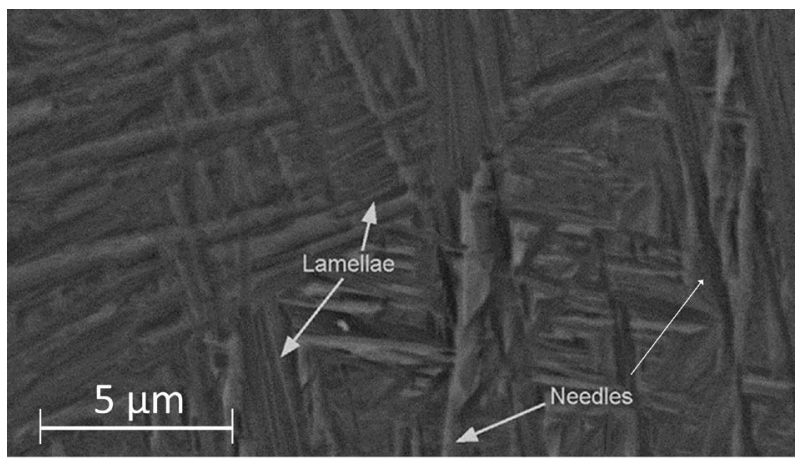

Figure 8. Microstructure obtained in the $\alpha+\beta$ phase. Finer lamellae microstructure embedded in martensite, separated by larger needles, obtained after holding in the $\alpha+\beta$ field and then quenching.
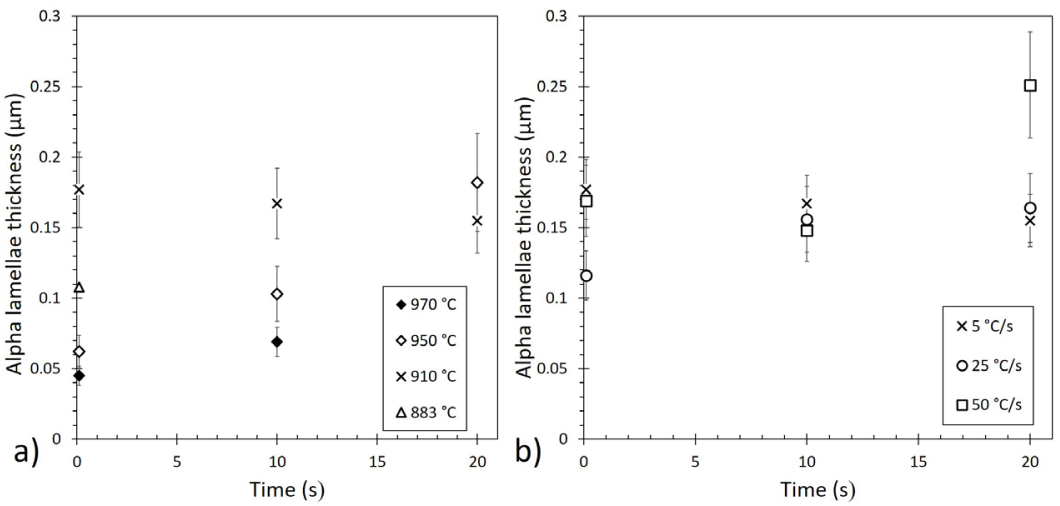

Figure 9. Effect on $\alpha$ lamellae thickness of; (a) soak temperature (with a constant cooling rate $=5^{\circ} \mathrm{C} / \mathrm{s}$ ), and (b) cooling rate (with a constant soak temperature $=910^{\circ} \mathrm{C}$ ).
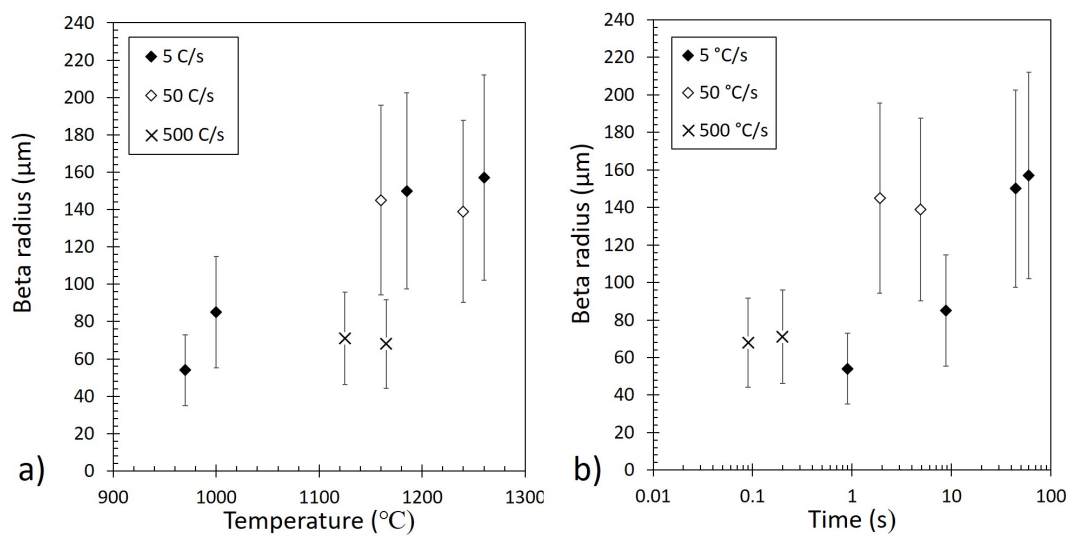

Figure 10. $\beta$ grain size measurements versus; (a) peak temperature as a function of the heating rate, and (b) time, as a function of the heating rate. 


\section{Numerical Modeling \& Validation}

\subsection{Beta Grain Growth}

To describe the $\beta$ phase microstructure evolution above the $\beta$-transus, the phenomenological solution proposed in literature [27] and [28] has been modified. In this approach, the $\beta$ grain dimension data obtained from isothermal heat treatments are fitted to Equation (1).

$$
d^{n}-d_{0}^{n}=A \times t \times \mathrm{e}^{-(Q / R T)}
$$

where $d=$ final grain size $(\mu \mathrm{m}), d_{0}=$ starting grain size $(\mu \mathrm{m}), t=$ time $(\mathrm{s}), Q=$ activation energy for grain growth $(\mathrm{J} / \mathrm{mol}), R=$ gas constant $\left(8.314 \mathrm{~J} \cdot \mathrm{mol}^{-1} \cdot \mathrm{K}^{-1}\right)$, $T=$ temperature (in Kelvin) and $A$ and $n$ material-specific constants.

The differential form of Equation (1) was adopted in literature [26] to describe the $\beta$ grain growth in Ti-6Al-4V for constant heating rate heat treatment. However, the work only reported good agreement between experiments and numerical predictions at relatively low temperatures. Thus the original form of Equation 1 was adopted, adding a correction term to match the asymptotic trend shown by the grain growth which would take into account the slower kinetics of the beta grains coarsening. The inverse tangent function was used to provide an asymptotic trend to Equation (1) that otherwise would predict exponential behavior for non-constant times and temperatures, see Equations (2) \& (3):

$$
d^{n}-d_{0}^{n}=A \times t \times \mathrm{e}^{-\left(Q / R T_{2}\right)}
$$

where;

$$
T_{2}=\tan ^{-1}(-T / B) \times\left(B / \tan ^{-1}(1)\right)
$$

Thus $T_{2}$ represents a correction factor, $B$ is a constant to be fitted to experimental data. A set of parameters was obtained by fitting Equation (2) and Equation (3) to the experimental data points of Figure 10(a). These parameter values are reported in Table 3, and relative grain growth predictions obtained are shown in Figure 11. Since a unique set of parameters for Equation (2) was employed, greater importance was applied to the faster cooling rates, as the study was focused on developing models to be used in rapid processes involving high temperature rates. Otherwise, activation energy as a function of temperature was used [29].

Although the range of temperature rates considered in this work is relatively wide, the $\beta$ grain growth kinetics, with asymptotic trend at high heating rates, is approximated. In particular, the experimental and numerical results are in good agreement at $500^{\circ} \mathrm{C} / \mathrm{s}$ heating rate. The maximum error obtained is at $50^{\circ} \mathrm{C} / \mathrm{s}$ rate, with a $20 \%$ error. The $5^{\circ} \mathrm{C} / \mathrm{s}$ model fits the data well at the $\beta$ transus temperature and at high temperatures, however the predicted evolution of this beta grain size differs compared to experiment at intermediate temperatures. The errors result from simplifications made in the phenomenological approximation.

Once the variation of the $\beta$-transus temperature as a function of the heating rate is known, for the alloy desired, using curve-fitting methods proposed [30] and successfully adapted [31] within literature, Equation (2) can be applied to 


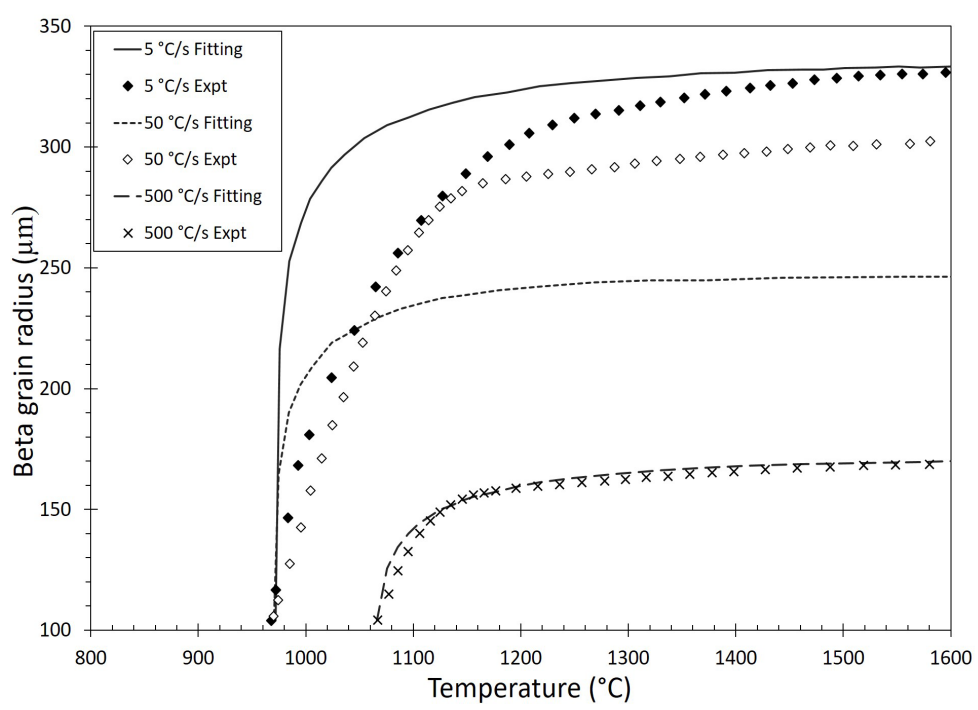

Figure 11. Comparison of experimental data and numerical model fitting of the $\beta$ grain growth at different heating rates $\left(5^{\circ} \mathrm{C} / \mathrm{s}, 50^{\circ} \mathrm{C} / \mathrm{s}\right.$ and $\left.500^{\circ} \mathrm{C} / \mathrm{s}\right)$.

Table 3. Parameters obtained from the current work by fitting Equation (2) to the experimental results.

\begin{tabular}{cccc}
\hline $\mathbf{n}$ & $\mathrm{A}\left[\mu \mathrm{m}^{2} \cdot \mathrm{s}^{-1}\right]$ & $\mathrm{Q}\left[\mathrm{J} \cdot \mathrm{mol}^{-1}\right]$ & $\mathrm{B}$ \\
\hline 7 & $4.262 \times 10^{8}$ & 100,000 & 1000 \\
\hline
\end{tabular}

predict the $\beta$ grain growth evolution as a function of unknown heating rates. Experimental validation data for such extreme thermal conditions are sparse in the literature, but the model appears to describe the trend, with the dimension of the $\beta$ grains almost unchanged for very high heating rates.

\subsection{Growth of Nucleated Alpha Lamellae}

The $\alpha$ lamellae nucleation and growth, cooling down from the $\beta$ field, has been described by an experimentally-derived equation (Equation (4)) that takes into consideration the two main factors affecting the final lamellae thickness, namely the $\beta$ grain size and the cooling rate the material is subjected to.

$$
\text { lamellae thickness }=-0.00130(\mathrm{~d} T / \mathrm{d} t)+0.0787 \ln (d)
$$

where $d$ is the mean $\beta$ grain size diameter in which lamellae nucleate and grow. The parameters of Equation (4) were obtained by fitting to the experimental data, adding some estimated points at $100^{\circ} \mathrm{C} / \mathrm{s}$ and $300^{\circ} \mathrm{C} / \mathrm{s}$ to the ones collected experimentally in this work, such to have a sufficient wide range of $\beta$ grain dimensions to let the fitting algorithm work.

Prediction of the lamellar thickness obtained applying Equation (4) to a series of $\beta$ grain radii, from 0 to $900 \mu \mathrm{m}$, and cooling rates of $5^{\circ} \mathrm{C} / \mathrm{s}, 50^{\circ} \mathrm{C} / \mathrm{s}, 100^{\circ} \mathrm{C} / \mathrm{s}$ and $300^{\circ} \mathrm{C} / \mathrm{s}$, are shown in Figure 12. The trends obtained from Equation (4) for cooling rates ranging from $5^{\circ} \mathrm{C} / \mathrm{s}$ to $300^{\circ} \mathrm{C} / \mathrm{s}$ are compared to experiment. For faster cooling rates and constant $\beta$ grain size, the lamellae thickness obtained after heat treatment is smaller than at a slow cooling rate. 


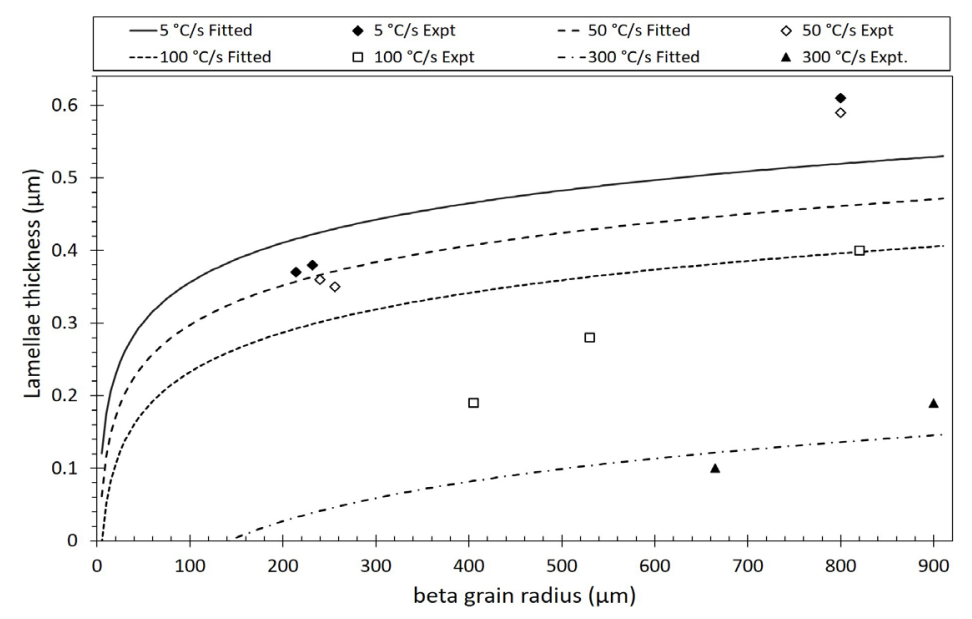

Figure 12. Comparison of $\alpha$ lamellae thickness model predictions (using Equation (4)) with the available experimental data.

This is hypothesised to be due to the shorter time lamellae have to grow with faster cooling rates. Also, for constant cooling rate, the bigger the $\beta$ grain, the thicker the lamellae are at the end of the thermal process. As discussed earlier a bigger $\beta$ grain volume allows nucleation of lamellae statistically more spaced and, as result, will impinge on themselves at a later stage of the diffusion growth.

\subsection{Martensitic Model}

The martensitic phase fraction evolution has been described as a function of the cooling rate by fitting an equation to the experimental data collected previously (in Figure $7(b)$ ). This model is based on the hypothesis that upon cooling the material from temperatures above $\beta$-transus, the $\beta$ phase fraction not transformed to $\alpha$ phase is entirely transformed to martensite, as the cooling rates considered are fast enough to convert the residual $\beta$ phase to martensite. This relationship is given in Equation (5).

$$
\alpha^{\prime} \text { vol fraction }=20.4 \times\left(2.62+\tan ^{-1}\{[\mathrm{~d} T / \mathrm{d} t]-65.0\}\right)
$$

The coarsening of the martensitic needles has been described by Equation (6), based on previous microstructural observations.

$$
\text { Needle thickness }=0.0895 \ln [\mathrm{d} T / \mathrm{d} t]-0.138
$$

Comparison between the experimental measurement of the martensitic phase fraction and the numerical predictions using Equation (5) is presented in Figure 13(a). A good match between the model and experimental data is observed.

Martensite appears to form in low quantities of approximately $20 \%$ at low cooling rates (eg: the experimentally measured $5^{\circ} \mathrm{C} / \mathrm{s}$ ), however this experiences a considerable increase at a cooling rate of approximately $60^{\circ} \mathrm{C} / \mathrm{s}$ to $80^{\circ} \mathrm{C} / \mathrm{s}$, increasing to $85 \%$ of volume fraction of material transformed for cooling rates of $80^{\circ} \mathrm{C} / \mathrm{s}$ and faster. The martensitic volume fraction can be well fitted by an arctangent function with a knee between $50^{\circ} \mathrm{C} / \mathrm{s}$ and $100^{\circ} \mathrm{C} / \mathrm{s}$. In absence of experimental data, at $410^{\circ} \mathrm{C} / \mathrm{s}$ the alloy is supposed to have a full martensitic transformation as stated in [24], which is a faster cooling rate than considered in this work. 

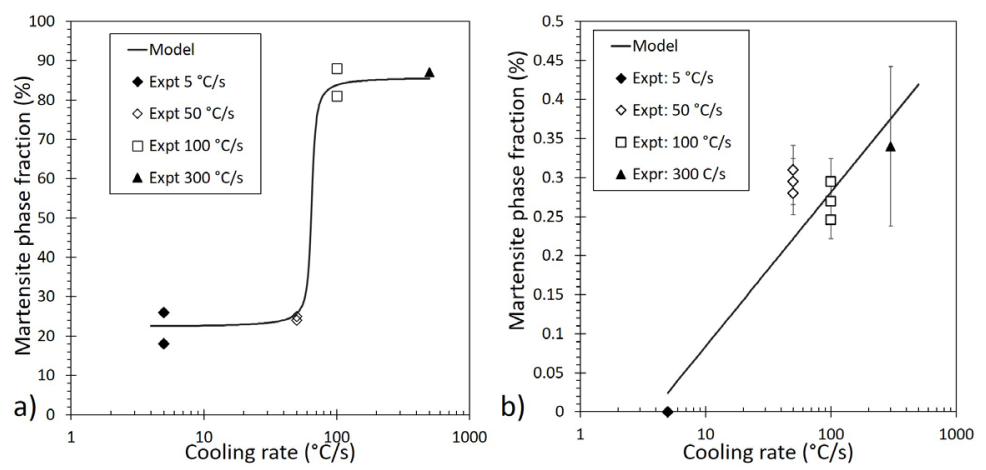

Figure 13. (a) Martensite phase-fraction as function of cooling rate, (b) needle thickness as function of cooling rate.

A logarithmic relationship between cooling rate and martensitic needle thickness (Equation (6)) appears to describe well the thickening of martensitic needles (see Figure 13(b)). The cooling rate seems to be the primary factor affecting the final thickness of the martensitic needles, whilst $\beta$ grain dimension is only of secondary importance.

\section{Conclusions}

Phenomenological and experimentally derived equations were adopted to describe: 1) $\beta$ grain nucleation and growth; 2) lamellae nucleation and growth when cooling down from above the $\beta$-transus temperature, and; 3) martensite formation. These phenomelogical models allow for the description of phase changes by relatively simple equations. Thus, they offer possible implementation in finite element simulations for industrial applications where computational times are important.

- The $\beta$ grain growth was essentially exponential in nature and has been described using a phenomenological equation widely used in the literature. A physically-based approach would have been necessary to describe nucleation and growth competition of the $\beta$ grains, however this is not well developed in the literature. For very fast heating rates (e.g. welding), validation data for the physically based equations at such high heating rates is very limited. This approach adopted allowed for modeling able to predict reasonable $\beta$ grain growth values for very fast heating rates from a small number of experiments.

- Alpha lamellae growth during cooling from temperatures above the $\beta$-transus temperature could be described as logarithmic and was approximated by an empirically derived equation, determining the main factors affecting the microstructure evolution to produce an analytical expression. The fit to experimental data was better at higher heating rates.

- The martensite transformation demonstrated the characteristic sigmoidal behavior characteristic of the diffusionless reaction. The martensite phase fraction and associated needle formation during cooling from above $\beta$-transus were predicted by an empirical function with reasonable accuracy. The phase fraction model, using an arctangent function captured the transition to the 
martensite phase accurately. The needle thickness predictions were reasonable when compared to experimental data.

- Satisfactory results were obtained by using these models. However, when applied to a microstructure different to the one to which they were calibrated, numerical uncertainties will increase and require further experimental calibration. However, pragmatically it must be accepted that this limitation is in the intrinsic nature of the approach.

\section{Acknowledgements}

The authors wish to thank ESI Group for the financial support offered toward the $\mathrm{PhD}$ project, of which this work formed a part. Many thanks to Frederic Boitout, of ESI Group, Lyon, for technical support and supervision. Thanks are offered to technical staff at Wilde Analysis (Stockport, UK) for induction heating FE modeling support. Thanks to colleagues at the University of Birmingham for training provided with the optical microscopy and electron microscopy facilities.

\section{Conflicts of Interest}

The authors declare no conflicts of interest regarding the publication of this paper.

\section{References}

[1] Boyer, R.R. (1996) An Overview on the Use of Titanium in the Aerospace Industry. Materials Science and Engineering: A, 213, 103-114. https://doi.org/10.1016/0921-5093(96)10233-1

[2] Mendez, P.F. and Eagar, T.W. (2001) Welding Processes for Aeronautics. Advanced Materials and Processes, 159, 39-43.

[3] Avrami, M. (1939) Kinetics of Phase Change. I General Theory. The Journal of Chemical Physics, 7, 1103-1112. https://doi.org/10.1063/1.1750380

[4] Avrami, M. (1940) Kinetics of Phase Change. II Transformation-Time Relations for Random Distribution of Nuclei. The Journal of Chemical Physics, 8, 212-224. https://doi.org/10.1063/1.1750631

[5] Avrami, M. (1941) Granulation, Phase Change, and Microstructure Kinetics of Phase Change. III. The Journal of Chemical Physics, 9, 177-184. https://doi.org/10.1063/1.1750872

[6] ESI-Group SYSWELD (2012) 2013 Reference Manual. ESI-Group.

[7] Ding, R., Guo, Z.X. and Wilson, A. (2002) Microstructural Evolution of a Ti-6Al-4V Alloy during Thermomechanical Processing. Materials Science and Engineering. $A$, 327, 233-245. https://doi.org/10.1016/S0921-5093(01)01531-3

[8] Tiley, J., Searles, T., Lee, E., Kar, S., Banerjee, R., Russ, J. and Fraser, H. (2004) Quantification of Microstructural Features in $\alpha / \beta$ Titanium Alloys. Materials Science and Engineering: A, 372, 191-198. https://doi.org/10.1016/j.msea.2003.12.008

[9] Gil, F.J., Manero, J.M., Ginebra, M.P. and Planell, J.A. (2003) The Effect of Cooling Rate on the Cyclic Deformation of $\beta$-Annealed Ti-6Al-4V. Materials Science and Engineering: A, 349, 150-155. https://doi.org/10.1016/S0921-5093(02)00784-0 
[10] Guo, B., Semiatin, S.L. and Jonas, J.J. (2019) Dynamic Transformation during the High Temperature Deformation of Two-Phase Titanium Alloys. Materials Science and Engineering. A, 761, Article ID: 138047. https://doi.org/10.1016/j.msea.2019.138047

[11] Guo, B., Semiatin, S.L., Jonas, J.J. and Yue, S. (2018) Dynamic Transformation of Ti-6Al-4V during Torsion in the Two-Phase Region. Journal of Materials Science, 53, 9305-9315. https://doi.org/10.1007/s10853-018-2237-0

[12] Jonas, J.J., Aranas, C., Fall, A. and Jahazi, M. (2017) Transformation Softening in Three Titanium Alloys. Materials and Design, 113, 305-310. https://doi.org/10.1016/j.matdes.2016.10.039

[13] Wang, K., Liu, G., Tao, W., Zhao, J. and Huang, K. (2017) Study on the Mixed Dynamic Recrystallization Mechanism during the Globularization Process of Laser-Welded TA15 Ti-Alloy Joint under Hot Tensile Deformation. Materials Characterization, 126, 57-63. https://doi.org/10.1016/j.matchar.2017.01.030

[14] Matsumoto, H., Velay, V. and Chiba, A. (2015) Flow Behavior and Microstructure in Ti-6Al-4V Alloy with an Ultrafine-Grained $\alpha$-Single Phase Microstructure during Low-Temperature-High-Strain-Rate Superplasticity. Materials and Design, 66, 611-617. https://doi.org/10.1016/j.matdes.2014.05.045

[15] Lutjering, G. (1998) Influence of Processing on Microstructure and Mechanical Properties of $(\alpha+\beta)$ Titanium Alloys. Materials Science and Engineering. A, 243, 32-45. https://doi.org/10.1016/S0921-5093(97)00778-8

[16] Fan, X., Jiang, X., Zeng, X., Shi, Y., Gao, P. and Zhan, M. (2018) Modeling the Anisotropy of Hot Plastic Deformation of Two-Phase Titanium Alloys with a Colony Microstructure. International Journal of Plasticity, 104, 173-195.

https://doi.org/10.1016/j.ijplas.2018.02.010

[17] Babu, B. and Lindgren, L.E. (2013) Dislocation Density Based Model for Plastic Deformation and Globularization of Ti-6Al-4V. International Journal of Plasticity, 50, 94-108. https://doi.org/10.1016/j.ijplas.2013.04.003

[18] Basoalto, H.C. (2017) On the Micromechanics of Slip of Two-Phase Titanium Alloys, International Conference on Plasticity, Damage and Fracture, Puerto Vallarta, Mexico.

[19] Panwisawas, P., Sovani, Y., Turner, R.P., Brooks, J.W., Basoalto, H.C. and Choquet, I. (2018) Modelling of Thermal Fluid Dynamics for Fusion Welding. Journal of Materials Processing Technology, 252, 176-182. https://doi.org/10.1016/j.jmatprotec.2017.09.019

[20] Wang, M., Yang, H., Zhang, C. and Guo, L.-G. (2013) Microstructure Evolution Modeling of Titanium Alloy Large Ring in Hot Ring Rolling. The International Journal of Advanced Manufacturing Technology, 66, 1427-1437. https://doi.org/10.1007/s00170-012-4420-9

[21] Kotkunde, N., Krishnamurthy, H.N., Puranik, P., Gupta, A.K. and Singh, S.K. (2014) Microstructure Study and Constitutive Modeling of Ti-6Al-4V Alloy at Elevated Temperatures. Materials and Design, 54, 96-103. https://doi.org/10.1016/j.matdes.2013.08.006

[22] Bai, W., Sun, R. and Leopold, J. (2016) Numerical Modelling of Microstructure Evolution in Ti6Al4V Alloy by Ultrasonic Assisted Cutting. Procedia CIRP, 46, 428-431. https://doi.org/10.1016/j.procir.2016.03.122

[23] Sieniawski, J., Ziaja, W., Kubiak, K. and Motyka, M. (2013) Titanium Alloys-Advances in Properties Control. IntechOpen, London. https://doi.org/10.5772/49999 
[24] Rostamian, A. and Jacot, A. (2008) A Numerical Model for the Description of the Lamellar and Massive Phase Transformations in TiAl Alloys. Intermetallics, 16, 1227-1236. https://doi.org/10.1016/j.intermet.2008.07.008

[25] Ahmed, T. and Rack, H.J. (1998) Phase Transformations during Cooling in $\alpha+\beta$ Titanium Alloys. Materials Science and Engineering: A, 243, 206-211. https://doi.org/10.1016/S0921-5093(97)00802-2

[26] Ivasishin, O.M., Semiatin, S.L., Markovsky, P.E., Shevchenko, S.V. and Ulshin, S.V. (2002) Grain Growth and Texture Evolution in Ti-6Al-4V during Beta Annealing under Continuous Heating Conditions. Materials Science and Engineering. A, 337, 88-96. https://doi.org/10.1016/S0921-5093(01)01990-6

[27] Soper, J.C., Directorate, M. and Base, W.A.F. (1996) Short-Time Beta Grain Growth Kinetics for a Conventional Titanium Alloy. Acta Metallurgica, 44, 1979-1986. https://doi.org/10.1016/1359-6454(95)00311-8

[28] Shen, G., Furrer, D. and Rollins, J. (1996) Advances in Science \& Technology of Titanium Alloy Processing. The Minerals, Metals \& Materials Society, Warrendale, 75-82.

[29] Malinov, S., Guo, Z., Sha, W. and Wilson, A. (2001) Differential Scanning Calorimetry Study and Computer Modeling of $\beta \Rightarrow \alpha$ Phase Transformation in a Ti-6Al-4V Alloy. Metallurgical and Materials Transactions A, 32, 879-887. https://doi.org/10.1007/s11661-001-0345-X

[30] Mittemeijer, E.J., Van Gent, A. and Van der Schaaf, P.J. (1986) Analysis of Transformation Kinetics by Nonisothermal Dilatometry. Metallurgical and Materials Transactions A, 17, 1441-1445. https://doi.org/10.1007/BF02650126

[31] Villa, M., Brooks, J.W., Turner, R.P., Wang, H., Boitout, F. and Ward, R.M. (2019) Microstructural Modeling of the $\alpha+\beta$ Phase in Ti-6Al-4V: A Diffusion-Based Approach. Metallurgical and Materials Transactions B, 50, 2898-2911. https://doi.org/10.1007/s11663-019-01675-0 